\title{
Electron probe micro-analysis of oxygen in cordierite: potential implications for the analysis of volatiles in minerals
}

\author{
Martin Rigby \\ Department of Geology, University of Pretoria, Pretoria, 0002, South Africa \\ e-mail: martin.rigby@up.ac.za \\ Giles Droop and David Plant \\ Department of Earth, Atmospheric and Environmental Science, University of Manchester, \\ Oxford Road, Manchester, M13 9PL, United Kingdom \\ e-mail: giles.droop@manchester.ac.uk; david.plant@manchester.ac.uk \\ Peter Gräser \\ Department of Geology, University of Pretoria, Pretoria, 0002, South Africa \\ e-mail: peter.graser@up.ac.za \\ (C) 2008 September Geological Society of South Africa
}

\begin{abstract}
The oxygen content of cordierite was analysed in 30, well-characterised samples, using electron probe micro-analysis (EPMA). The major elements were assumed to be stoichiometric and therefore any remaining oxygen from the analysis can be attributed to volatile oxygen, which is defined as the oxygen in $\mathrm{H}_{2} \mathrm{O}$ and/or $\mathrm{CO}_{2}$ within cordierite's channel structure. The EPMA volatile oxygen contents were compared to volatile oxygen contents obtained from the same samples using secondary-ion mass spectrometry (SIMS) and Fourier-transform infra-red spectroscopy (FTIR). There is a correlation between the data obtained by EPMA and the independent techniques. The data suggests that light-elements, such as oxygen, can be analyzed routinely on the electron microprobe with a degree of accuracy approaching the levels obtained by other, well-established methods. EPMA of oxygen, in addition to the major cations, provides a valuable tool for analyzing the $\mathrm{H}_{2} \mathrm{O} / \mathrm{OH}^{-}$and/or volatile oxygen content of minerals such as amphiboles, micas and cordierite. The assumption implicit in this method, however, relies upon the fact that oxygen is stoichiometric with the major cations. If non-stoichiometry does apply then the method for calculating either $\mathrm{H}_{2} \mathrm{O}$ or volatile oxygen is rendered inadequate.
\end{abstract}

\section{Introduction}

Electron probe micro-analysis (EPMA) is the standard 'work horse' technique used in mineralogy and petrology (coupled with optical microscopy and diffraction methods). EPMA provides a rapid, relatively cheap, non-destructive, in-situ analysis with high spatial resolution, good accuracy and low detection limits. EPMA utilizes the X-ray spectrum emitted from a solid sample bombarded by a focused beam of accelerated electrons to obtain a localized (micro) chemical analysis. All elements from $\mathrm{Na}(Z=11)$ through to $U(Z=92)$ can be routinely analyzed. However, the latest generation of EPMA instruments incorporates capabilities for the quantitative analysis of light-elements $(Z<10)$. Light element $\mathrm{X}$-ray emissions are characterized by low energies and long wavelengths (Goldstein et al., 1992). These lines lie beyond the wavelength range of conventional crystals used in wavelength dispersive spectrometers (WDS). The advent of layered synthetic microstructure (LSM) crystals (sometimes called synthetic multilayer crystals, pseudo-crystals or layered dispersion elements) with large inter-planar spacing enables the coverage of elements to be extended, in theory, to Be (Raudsepp, 1995).

These technological advancements have important ramifications for the analysis of most geological materials whose modal element composition is dominated by oxygen bearing compounds. The determination of oxygen via EPMA would be particularly useful for minerals such as micas, amphiboles and cordierite, which contain appreciable amounts of either structurally bound $\mathrm{H}_{2} \mathrm{O}$ or hydroxyl groups $\left(\mathrm{OH}^{-}\right)$and invariably yield low analytical totals via conventional EPMA. The direct analysis of oxygen in addition to the major cations would enable the $\mathrm{H}_{2} \mathrm{O}$ and/or $\mathrm{OH}^{-}$content of minerals to be calculated by difference.

Despite the technological advancements enabling the analysis of light elements via EPMA there has been a notable lack of published material exploiting this potentially powerful method; this has ultimately led to a great deal of skepticism regarding the potential use of light-element electron probe micro-analysis. In this paper we present EPMA-determined total-volatile oxygen contents (oxygen from $\mathrm{H}_{2} \mathrm{O}+$ oxygen from $\mathrm{CO}_{2}$ ) for a suite of cordierite samples whose volatile contents $\left(\mathrm{H}_{2} \mathrm{O}\right.$ and $\left.\mathrm{CO}_{2}\right)$ have been determined independently by various analytical techniques (SIMS, FTIR). This approach enables the effectiveness of EPMA to be vetted against traditional, well-established techniques.

\section{Light Element Electron Probe Microanalysis} General analytical conditions and considerations

Light element X-ray emissions have low energies and long wavelengths. These lines lie beyond the 
wavelength range of conventional crystals used in wavelength dispersive spectrometers (WDS). The advent of layered synthetic microstructure (LSM) has brought about considerable improvements to the analysis of light elements. These improvements consist of a significant increase in the peak count rates of light elements and the suppression of high-order reflections (Goldstein et al., 1992). In the WDS system there is the potential of interference from high-order metal lines with the lightelement lines, such as $\mathrm{Cr}, \mathrm{Mn}, \mathrm{Fe}$ and $\mathrm{Ni}$ and the group $\mathrm{Zr}$, Nb and Mo. As pointed out by Bastin and Heijligers (1990), due to the proximity of the $\mathrm{M}_{5}$ absorption edge, the latter group causes problems with most of the light elements. The pulse height analyser can be set to a rather narrow window in an attempt to remove these high-order lines. The performance of LSM crystals relative to their conventional counterparts has been studied exhaustively. For example, Bastin and Heijligers (1991) recorded nitrogen spectra from $\mathrm{ZrN}$ with a conventional STE crystal and a LDE. This study found a large increase in $\mathrm{N}$ count rates and the remnants of highorder $\mathrm{Zr}$-reflections present on the STE crystal are suppressed on the LDE crystal, consequently yielding a smooth background and low peak-to-background ratios. Moreover, Bastin and Heijligers (1991) demonstrated the inimitable sensitivity of the LSM crystals (in this case their LDE crystal) for $\mathrm{O} \mathrm{K} \alpha$, whereby an $\mathrm{O}$ peak was detected on pure gold. This demonstrates how surfacesensitive a microprobe can be, as the solid solubility of $O$ in pure gold is negligible.

In spite of technological advances, spectral problems still plague the routine analysis of light-elements. Bastin and Heijligers $(1986 ; 1990)$ established that these new multi-layer crystals are much more sensitive to peak shape and shift alterations in the light-element X-ray emission peaks than their conventional counterparts. This is attributed, in part, to the inferior resolution of the older crystals. For the light elements, the X-ray emission spectra consist mainly of a single band produced by the transition of a valence electron from the unfilled $2 \mathrm{~d}$ subshell to a vacancy in the $\mathrm{K}$ shell. These valence electrons are most likely to be dependent on the local chemical bonding environment and consequently will initiate changes in the characteristics of the $\mathrm{K}$ spectra (Fischer, 1964; Bastin and Heijligers, 1990). These changes are signified by wavelength shifts, by increases or decreases in the relative intensities of various lines or bands, and by alteration of peak shapes.

Armstrong (1988) noted that O Ka peak shapes are similar in different compounds, but not identical. Measured differences in the ratio of the peak height to the net area of the peak were 3\% more for $\mathrm{MgO}$ than for $\mathrm{Al}_{2} \mathrm{O}_{3}$, about $4 \%$ less for $\mathrm{SiO}_{2}$ than for $\mathrm{Al}_{2} \mathrm{O}_{3}$, and about $13.5 \%$ less for $\mathrm{TiO}_{2}$ than for $\mathrm{SiO}_{2}$. Furthermore, Bastin and Heijligers (1991) illustrated how such changes can also influence the $\mathrm{C} \mathrm{Ka}$ peak shapes of two different C-bearing compounds. They showed that the peak emitted from glassy carbon is approximately twice as wide as that from $\mathrm{TiC}$, yielding an error of up to $50 \%$ when the effects of peak shape alteration are neglected. These differences necessitate the use of either (a) a standard similar in composition to the unknown or (b) the use of a robust correction procedure. Peak measurements are commonly only correct under the tacit assumption that the peak intensity is proportional to the overall integral emitted intensity (Bastin and Heijligers, 1990; Bastin and Heijligers, 2000). For the heavier element lines this assumption is correct; conversely, for the light elements this assumption is far from valid. In order solve this problem Bastin and Heijligers (2000) pioneered the use of the area-peak factor (APF). This has been defined as the ratio between the correct integral (or area) $k$-ratio and the peak $k$-ratio. The APF is only valid for a given compound with respect to a given standard and for a given spectrometer with its own unique light element crystal with a specific resolution. Bastin and Heijligers (2000) state that once an APF has been determined future measurements on the compound in question can be simply carried out on the peak; subsequent multiplication of the peak $k$-ratio with the APF will then yield the correct integral ratio.

\section{Accelerating voltage}

Voltage should be set to produce optimum count rates for reliable measurements of all elements of interest in a known matrix. Traditionally, $15 \mathrm{kV}$ has been used for the analysis of geological materials, partly to optimise for iron; however, McGee and Anovitz (1996) suggest $10 \mathrm{kV}$ is more suitable for light-element analysis, as their intensities reach maximum values at relatively low accelerating voltages. At higher voltages, beam penetration increases and generates X-rays from a larger excitation volume, but more absorption of the X-rays occurs, resulting in a decrease in X-ray intensities (Goldstein et al., 1992). Light-element X-ray analysis should be carried out at an electron-beam energy, where the maximum intensity of the light-element X-ray of interest is obtained.

\section{Beam current}

Even with LSM crystals, light-element count rates are still relatively low in geologic materials. McGee and Anovitz (1996) suggest the use of relatively high currents to produce better counting statistics. However, as pointed out by Bastin and Heijligers (1990), this increase in beam current may lead to dead-time problems in the WDS system for the metal X-ray lines, since these intensities are usually measured simultaneously with the light elements. The dead-time problems can be avoided by either measuring the metals and light elements separately, both under optimum conditions, with obvious experimental disadvantages, or by using higher order metal lines (Goldstein et al., 1992). There is often concern for whether or not an element mobilizes during beam exposure. McGee and Anovitz (1996) found when analysing a variety of borosilicates using combined effects of high current usage and long beam exposure that there was no evidence for the loss of boron. 


\section{Counting times}

Longer counting times will improve statistics, but monitoring the effects of long beam exposure is important to ensure that contamination build-up, sample heating, or charge build-up does not affect X-ray intensities (McGee and Anovitz, 1996).

\section{Surface contamination}

The surface of a sample in contact with an electron beam often accumulates a layer of contamination, mainly consisting of carbon. This is caused by the interaction of the electron beam with traces of diffusion pump oil or hydrocarbons from dirty samples. This is an inconsequential problem in conventional analysis, but is much more significant for the light elements, since it causes enhancement of the $\mathrm{C} K \alpha$ intensity and reduction in the intensity of other lines due to absorption (Reed, 1993). The first step towards minimizing contamination is to ensure the samples are thoroughly clean. Samples should be kept in a vacuum storage facility to prevent contaminants in the air being deposited onto the surface, provided the vacuum pump is fitted with an oil trap (Raudsepp, 1995). The accumulation of contamination can be avoided by using a liquid-nitrogen-cooled cold finger, or by directing a gas jet at the impact point of the beam. The air jet not only inhibits hydrocarbon deposition but also removes surface impurities already present. Bastin and Heijligers (1988; 1990) studied the effects of contamination build-up and found the gas jet used in conjunction with a cold finger to be the most effective.

\section{Conducting layers}

Many geological materials are electrically nonconducting and therefore have to have an electrically conducting coat applied. The conducting coat has effects that are more severe for light-element analysis than for routine heavier elements. Armstrong (1993) demonstrated that variations in carbon coat thickness might generate systematic errors of greater than $1 \%$. A variation of the carbon coat thickness by $10 \mathrm{~nm}$ causes the $\mathrm{O} \mathrm{K} \alpha$ intensity to vary by $3.8 \%$ at an accelerating voltage of $15 \mathrm{kV}$. These effects can be minimized by coating specimens and standards simultaneously each time they are to be used, in order to obtain a uniform thickness (Reed, 1993). Armstrong (1988) adopted the practice of coating a sample of $\mathrm{Al}_{2} \mathrm{O}_{3}$ with each batch of specimens and measuring the $\mathrm{O} \mathrm{K} a$ intensity, from which the thickness of the carbon coat is deduced and used to estimate the correction for the specimen intensities. In certain circumstances it may be necessary to use another coating material instead of carbon, for example, where one requires the detection of low levels of carbon from within the sample. The carbon coat in this instance may seriously hinder the quantification process by drastically increasing the $\mathrm{C} \mathrm{K} a$ intensity. When using a different coating material the thickness and possible absorption effects of the coat must be determined in order to facilitate the quantification process (Raudsepp, 1993).

\section{Standards for EMPA}

EPMA is a relative analytical technique that relies on the comparison of X-ray lines from a sample with those of a well-characterized standard. This basis for quantification requires that the standards used for EPMA give strong, stable and reproducible peak intensities (Reed, 1995). Essentially, a standard similar in composition and structure to the unknown sample is used in order to minimize matrix effects and spectral variations such as peak-shift and shape alterations (Bastin and Heijligers, 1990; Goldstein et al., 1992; Reed, 1993). The standards should be homogeneous, well-characterized materials, in which the composition is independently established by other chemical techniques.

McGuire et al. (1992) studied a variety of minerals (proposed as potential oxygen standards) using fastneutron-activated analysis (FNAA) to independently determine the $\mathrm{O}$ content. The measured $\mathrm{O}$ contents were then compared to calculated $\mathrm{O}$ contents (assuming stoichiometry). The majority of samples were found to have stoichiometric O contents. Nevertheless, three out of the 13 samples studied had higher than expected $O$ contents. This accentuates the potential danger in assuming that a mineral standard will have a stoichiometric O content. McGuire et al., (1992) concluded that microprobe analysis of $\mathrm{O}$ should be carried out using standards whose $\mathrm{O}$ contents are measured or if stoichiometric criteria are used, one must determine the $\mathrm{Fe}^{3+} / \Sigma \mathrm{Fe}$ ratios in Fe-bearing standards and the $\mathrm{H}$ contents in hydrous mineral standards in order to calculate $\mathrm{O}$ with any degree of accuracy.

\section{Analytical success}

Nash (1992) reported the O concentration in various major-element mineral standards, hydrous minerals and samples of natural glass. The analyses were performed on a Cameca SX-50 electron microprobe at $15 \mathrm{kV}$ accelerating voltage, a beam current of $25 \mathrm{nA}$, and a beam diameter varying from 5 to $25 \mu \mathrm{m}$, and a counting time of 20 seconds. The $\mathrm{O}$ contents of 18 mineral standards were determined using synthetic $\mathrm{Al}_{2} \mathrm{O}_{3}$ for $\mathrm{O}$ calibration using the OVONYX OV-060a synthetic crystal. The correlation between/measured and nominal O contents (assuming stoichiometry) was found to be excellent. Nash (1992) concluded that direct O analyses can be performed routinely with a precision that is comparable and some instances better than that of silicon $(\sim 0.6 \%)$. In spite of the overall agreement, hematite and magnetite did show measured O contents that were low by 1 weight $\%$ absolute. Nash (1992) attributed this discrepancy to peak shape differences between the $\mathrm{Al}_{2} \mathrm{O}_{3}$ and the iron oxides, consequently emphasizing the need to apply the correction procedures of Bastin and Heijligers $(1986 ; 2000)$ or employ standards of similar composition in order to 


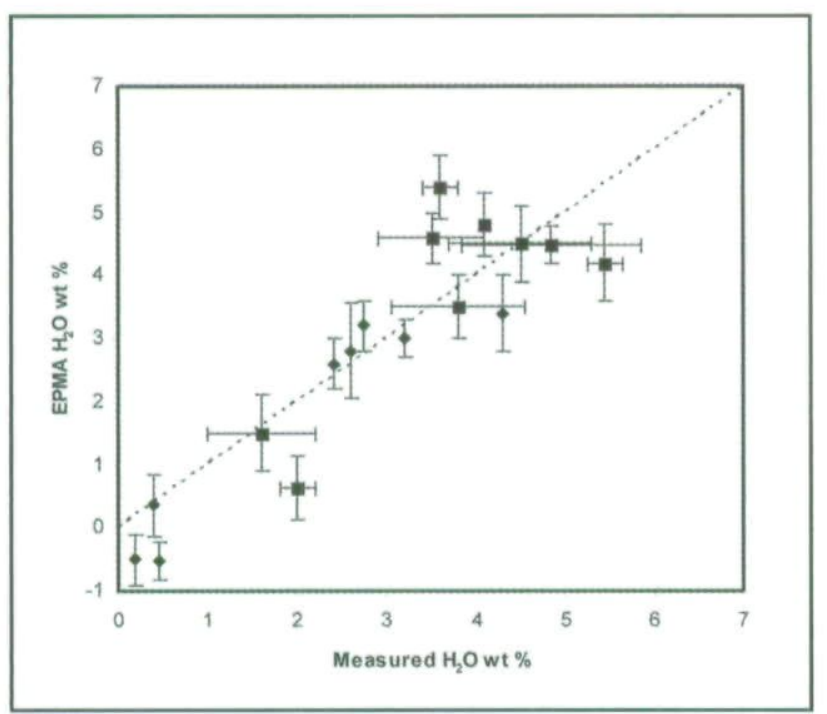

Figure 1. $\mathrm{H}_{2} \mathrm{O}$ content of hydrated glass estimated from EMPA versus $\mathrm{H}_{2} \mathrm{O}$ content determined by SIMS on melt inclusions (squares) and by $\mathrm{H}$-manometry on obsidian glass separates (diamonds). The error bars for EMPA values are standard deviations for ten analyses on each sample. SIMS error estimates are $0.5 \%$; manometry uncertainties are less than the size of the data points (Data from Nash, 1992).

reduce matrix effects when investigating minerals of unknown composition.

Further work by Nash (1992) demonstrated that the direct determination of $\mathrm{O}$ provides a measure of the quality of the analysis for cations (from the analytical total), and, providing the valence states are known (particularly important for Fe-bearing minerals), yields an indirect estimate of the $\mathrm{H}_{2} \mathrm{O}$ content of hydrous minerals and glasses by comparison of measured with stoichiometric $\mathrm{O}$ concentrations. Figure 1 illustrates the estimates of $\mathrm{H}_{2} \mathrm{O}$ contents determined using EMPA compared with measured $\mathrm{H}_{2} \mathrm{O}$ contents by SIMS and manometry. The EMPA concentrations agree within the level of precision with the results from botb manometry and SIMS. These encouraging results are supported by the earlier work of Armstrong (1988) who concluded that with care in carbon coating, in avoiding surface contamination and in the correction procedure used, quantitative analysis for $\mathrm{O}$ can be done with a degree of accuracy and precision approaching that of the other major elements.

\section{Analytical techniques and methodology EPMA of oxygen in cordierite}

The cordierite samples for this study have been subjected to the rigors of standard petrological investigation (e.g. mineral chemistry, geological context etc) and come from well-characterized areas:

1. The Etive thermal aureole, Scotland (Droop and Moazzen, 2007; Rigby et al., 2008) and

2. The Ballachulish thermal aureole, Scotland (Pattison and Harte, 1989; Rigby and Droop, 2008) and

3. Additional samples of gem-quality megacrystic cordierite come from three high-grade regionalmetamorphic terrains:

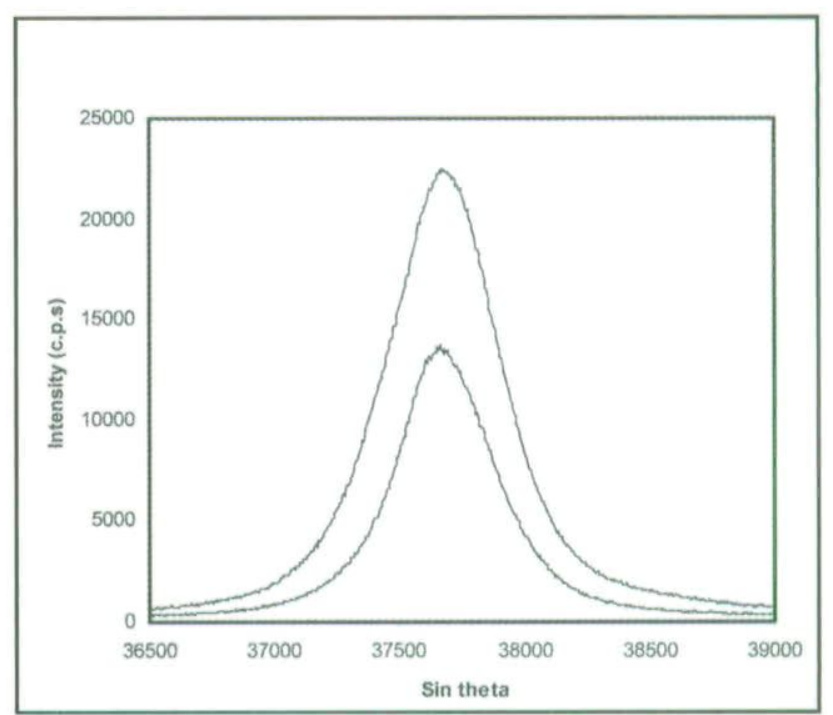

Figure 2. A comparison of the optimum oxygen count rates for crystals PC0 and PC1. PC1 is significantly more efficient than PC0. Spectral scans were performed at $10 \mathrm{kV}$ and $100 \mathrm{nA}$.

a. the Central Zone of the Limpopo Belt, Zimbabwe (Droop, 1989),

b. the Kodaikanal area of the S Indian granulite belt (Harris, 1981), and

c. the Orijarvi area of the Fennoscandian Shield, southwest Finland.

An assumption inherent to the method is that the major cations are stoichiometric, any remaining oxygen in cordierite can be attributed to volatile $\mathrm{O}$. Where, volatile $\mathrm{O}$ is equal to the oxygen from $\mathrm{H}_{2} \mathrm{O}$ and/or $\mathrm{CO}_{2}$. This approach enables the independently-determined volatile-O contents (SIMS and FTIR) to be compared to EPMA-determined volatile-O contents in order ascertain the effectiveness of this method.

Prior to analysis all samples and standards were wellpolished and thoroughly cleaned. Prior to each analytical session samples and standards were subjected to nine 3-minute sessions in an ultra-sonic bath, containing firstly, ethanol absolute (for three 3-minute sessions), then acetone (for three 3-minute sessions) and finally distilled water (for three 3-minute sessions). Care must be taken in order to ensure prolonged exposure to acetone does not degrade any bonding agent used in the construction of thin-sections or polished blocks. Samples and standards were coated simultaneously each analytical session to avoid variations in C coat thickness.

Analyses were performed on the state-of-the-art 5-spectrometer CAMECA SX-100 electron microprobe at the University of Manchester. The CAMECA SX-100 is equipped with five wavelength-dispersive spectrometers containing $\mathrm{PCO}$ and $\mathrm{PC} 1$ analyzing crystals that enable the quantification of $\mathrm{O}$. The efficiency of PCO and PC1 was tested by comparing the optimal $\mathrm{O}$ count rates obtained from each crystal during WDS spectral scans of cordierite sample AMNH. For a given accelerating voltage and beam current, analysing crystal PC1 records the optimal count rate (Figure 2) and consequently this crystal was employed in all subsequent quantitative $\mathrm{O}$ 
Table 1. Representative cordierite analyses and calculated volatile oxygen contents from the EMPA of samples from the Ballachulish thermal aureole.

\begin{tabular}{|c|c|c|c|c|c|c|c|c|c|c|}
\hline \multirow[t]{2}{*}{ Sample } & MRB & MRB & MRB & MRB & MRB & MRB & MRB & MRB & MRB & MRB \\
\hline & $2 c$ & 4 & 5 & 7 & 10 & 12 & 13 & 14 & 15 & $16 A$ \\
\hline \multicolumn{11}{|l|}{ wt. \% } \\
\hline $\mathrm{Fe}$ & 11.30 & 7.14 & 11.07 & 7.12 & 8.38 & 8.29 & 9.49 & 9.37 & 9.32 & 7.99 \\
\hline $\mathrm{Mn}$ & 0.12 & 0.32 & 0.15 & 0.32 & 0.33 & 0.57 & 0.23 & 0.20 & 0.23 & 0.21 \\
\hline $\mathrm{Al}$ & 16.68 & 17.36 & 16.85 & 17.23 & 17.18 & 17.25 & 17.16 & 17.11 & 17.13 & 17.28 \\
\hline $\mathrm{Si}$ & 21.95 & 22.38 & 21.90 & 22.36 & 22.00 & 22.07 & 22.18 & 22.04 & 22.15 & 22.19 \\
\hline $\mathrm{K}$ & 0.01 & 0.04 & 0.00 & 0.00 & 0.05 & 0.01 & 0.00 & 0.00 & 0.00 & 0.00 \\
\hline $\mathrm{Na}$ & 0.12 & 0.14 & 0.10 & 0.15 & 0.33 & 0.28 & 0.16 & 0.20 & 0.14 & 0.14 \\
\hline $\mathrm{Mg}$ & 2.71 & 4.68 & 2.84 & 4.65 & 3.91 & 3.86 & 3.60 & 3.62 & 3.68 & 4.26 \\
\hline $\mathrm{O}$ & 46.34 & 47.71 & 46.41 & 47.28 & 47.00 & 47.30 & 47.49 & 46.86 & 47.01 & 47.37 \\
\hline Total & 99.23 & 99.77 & 99.33 & 99.10 & 99.18 & 99.62 & 100.30 & 99.40 & 99.64 & 99.44 \\
\hline Stoichiometric $\mathrm{O}$ & 44.94 & 46.22 & 45.06 & 46.04 & 45.54 & 45.67 & 45.74 & 45.52 & 45.67 & 45.85 \\
\hline Volatile O & 1.40 & 1.49 & 1.35 & 1.23 & 1.46 & 1.63 & 1.76 & 1.34 & 1.33 & 1.52 \\
\hline Error $+/-$ & 0.12 & 0.15 & 0.15 & 0.11 & 0.15 & 0.17 & 0.15 & 0.15 & 0.14 & 0.16 \\
\hline
\end{tabular}

Table 2: Representative cordierite analyses and calculated volatile oxygen contents from the EMPA of samples from the Ballachulish thermal aureole

\begin{tabular}{|c|c|c|c|c|c|c|c|c|c|c|}
\hline \multirow[t]{2}{*}{ Sample } & MRB & MRB & MRB & MRB & MRB & MRB & MRB & MRB & MRB & MRB \\
\hline & 16D & $16 E$ & $16 \mathrm{~F}$ & $16 G$ & 19 & 21 & 22 & 23 & 24 & 25 \\
\hline \multicolumn{11}{|l|}{ Awt. $\%$} \\
\hline $\mathrm{Fe}$ & 8.19 & 8.27 & 8.34 & 8.75 & 6.20 & 7.12 & 6.46 & 7.36 & 7.39 & 9.64 \\
\hline Mn & 0.19 & 0.16 & 0.20 & 0.15 & 0.31 & 0.12 & 0.17 & 0.12 & 0.12 & 0.23 \\
\hline $\mathrm{Al}$ & 17.28 & 17.22 & 17.19 & 17.20 & 17.33 & 17.23 & 17.34 & 17.33 & 17.13 & 17.14 \\
\hline $\mathrm{Si}$ & 22.21 & 22.33 & 22.30 & 22.35 & 22.36 & 22.41 & 22.37 & 22.16 & 22.41 & 22.04 \\
\hline K & 0.00 & 0.00 & 0.00 & 0.00 & 0.07 & 0.00 & 0.00 & 0.01 & 0.03 & 0.00 \\
\hline $\mathrm{Na}$ & 0.12 & 0.13 & 0.12 & 0.12 & 0.25 & 0.14 & 0.19 & 0.16 & 0.14 & 0.10 \\
\hline $\mathrm{Mg}$ & 4.20 & 4.22 & 4.18 & 3.99 & 5.05 & 4.57 & 5.00 & 4.66 & 4.65 & 3.48 \\
\hline $\mathrm{O}$ & 47.08 & 47.39 & 47.33 & 47.44 & 47.98 & 47.58 & 47.56 & 47.44 & 47.46 & 46.64 \\
\hline Total & 99.27 & 99.72 & 99.67 & 100.01 & 99.56 & 99.17 & 99.09 & 99.24 & 99.33 & 99.28 \\
\hline Stoichiometric O & 45.88 & 45.99 & 45.94 & 45.98 & 46.18 & 45.98 & 46.17 & 45.93 & 46.03 & 45.52 \\
\hline Volatile $\mathrm{O}$ & 1.20 & 1.39 & 1.39 & 1.47 & 1.80 & 1.60 & 1.38 & 1.51 & 1.43 & 1.13 \\
\hline Error $+/-$ & 0.14 & 0.17 & 0.16 & 0.17 & 0.19 & 0.15 & 0.12 & 0.16 & 0.13 & 0.13 \\
\hline
\end{tabular}

Table 3: Representative cordierite analyses and calculated volatile oxygen contents from the EMPA of samples from the Etive thermal aureole (MM166A-MM193Y) and Orijarvi, Finland (799), Kodaikanal, S India (305), and the Limpopo Belt, Zimbabwe (BB14́b, 1016).

\begin{tabular}{|c|c|c|c|c|c|c|c|c|c|c|c|}
\hline \multirow[t]{2}{*}{ Sample } & MM & MM & MM & MM & $\mathbf{M M}$ & MM & MM & & & & \\
\hline & 166A & 166D & 171 & 174 & $186 a$ & 187 & 193Y & 799 & 305 & BB14B & 1016 \\
\hline \multicolumn{12}{|l|}{ Awt. \% } \\
\hline $\mathrm{Fe}$ & 8.78 & 8.91 & 8.64 & 8.44 & 8.82 & 8.77 & 8.10 & 3.74 & 1.28 & 2.32 & 1.88 \\
\hline Mn & 0,21 & 0.16 & 0.32 & 0.40 & 0.13 & 0.21 & 0.25 & 0.03 & 0.01 & 0.02 & 0.02 \\
\hline $\mathrm{Al}$ & 17.28 & 17.36 & 17.25 & 17.26 & 17.19 & 17.30 & 17.29 & 17.59 & 17.48 & 17.68 & 17.65 \\
\hline $\mathrm{Si}$ & 22.69 & 22.15 & 22.32 & 22.32 & 22.19 & 22.03 & 22.11 & 22.93 & 23.17 & 23.14 & 23.04 \\
\hline K & 0.00 & 0.00 & 0.01 & 0.01 & 0.00 & 0.00 & 0.00 & 0.00 & 0.00 & 0.00 & 0.00 \\
\hline $\mathrm{Na}$ & 0.07 & 0.05 & 0.10 & 0.11 & 0.13 & 0.13 & 0.11 & 0.04 & 0.29 & 0.17 & 0.21 \\
\hline $\mathrm{Mg}$ & 3.83 & 4.05 & 3.85 & 4.03 & 3.88 & 4.00 & 4.23 & 6.69 & 8.13 & 7.44 & 7.64 \\
\hline $\mathrm{O}$ & 47.19 & 47.07 & 47.53 & 47.20 & 46.89 & 47.18 & 47.24 & 48.38 & 49.11 & 49.24 & 49.20 \\
\hline Total & 100.05 & 99.74 & 100.02 & 99.77 & 99.24 & 99.63 & 99.33 & 99.41 & 99.48 & 100.01 & 99.65 \\
\hline Stoichiometric O & 46.34 & 45.95 & 45.91 & 46.01 & 45.74 & 45.74 & 45.79 & 47.27 & 47.77 & 47.72 & 47.60 \\
\hline Volatile $\mathrm{O}$ & 0.85 & 1.11 & 1.63 & 1.19 & 1.16 & 1.43 & 1.45 & 1.11 & 1.34 & 1.52 & 1.61 \\
\hline Error $+/-$ & 0.12 & 0.10 & 0.16 & 0.12 & 0.13 & 0.15 & 0.13 & 0.16 & 0.16 & 0.16 & 0.19 \\
\hline
\end{tabular}

analyses. The remaining spectrometers are equipped with TAP, PET and LiF analysing crystals. Analyses were performed at an accelerating voltage of $10 \mathrm{kV}$, a beam current of $20 \mathrm{nA}$, and a beam diameter ranging from $1-10 \mu \mathrm{m}$. O was measured at the beginning of each analysis in order to avoid any time-dependent contamination-related problems. The overall counting time for $\mathrm{O}$ was 30 seconds. The potential for elemental lines to interfere with the $O$ peak was determined using VIRTUAL WDS (Reed and Buckley, 1998). Only high 
order $\mathrm{Na}$ lines were found to overlap with the $\mathrm{O}$ peak. If $\sim 10$ weight $\% \mathrm{Na}$ is present in the sample this will cause a 2 to 3 weight $\%$ increase in the measured $\mathrm{O}$ content. These interference effects can be removed by setting the pulse-height analyzer to a narrow window. Background intensities were measured on both sides of the analytical peak. Concentrations were calculated from relative peak intensities using the internal PAPcorrection. The internal PAP software is based on the light-element-customized $\Phi(\rho z)$ algorithms of Pouchou and Pichoir (1991), which supersede the conventional ZAF correction procedures. A liquid nitrogen-cooled cold-finger and an air-jet were employed in order to prevent contamination build-up. It is imperative that both the air-jet and cold-finger are given sufficient time $(\sim 1 \mathrm{hr})$ to cool and/or stabilize.

Cordierite standard AMNH (used by Carrington and Harley, 1996; Moazzen et al., 2001 and Harley et al., 2002 has $\mathrm{XMg}=0.87 ; \mathrm{H}_{2} \mathrm{O}=1.56+/-0.08$ wt $\%$; and $\mathrm{CO}_{2}$

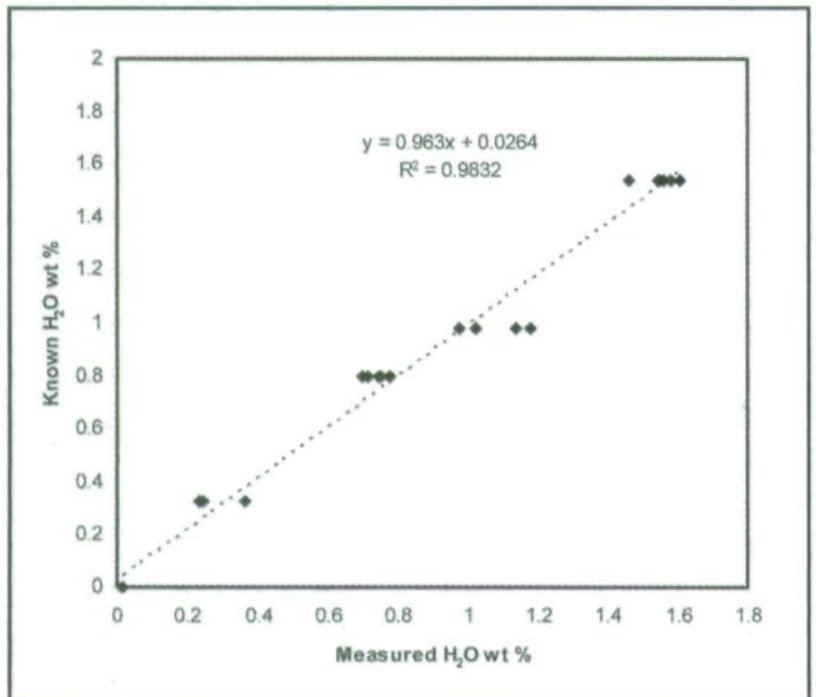

Figure 3. SIMS $\mathrm{H}_{2} \mathrm{O}$ calibration curve. A plot of known cordierite $\mathrm{H}_{2} \mathrm{O}$ content versus measured $\mathrm{H}_{2} \mathrm{O}$.

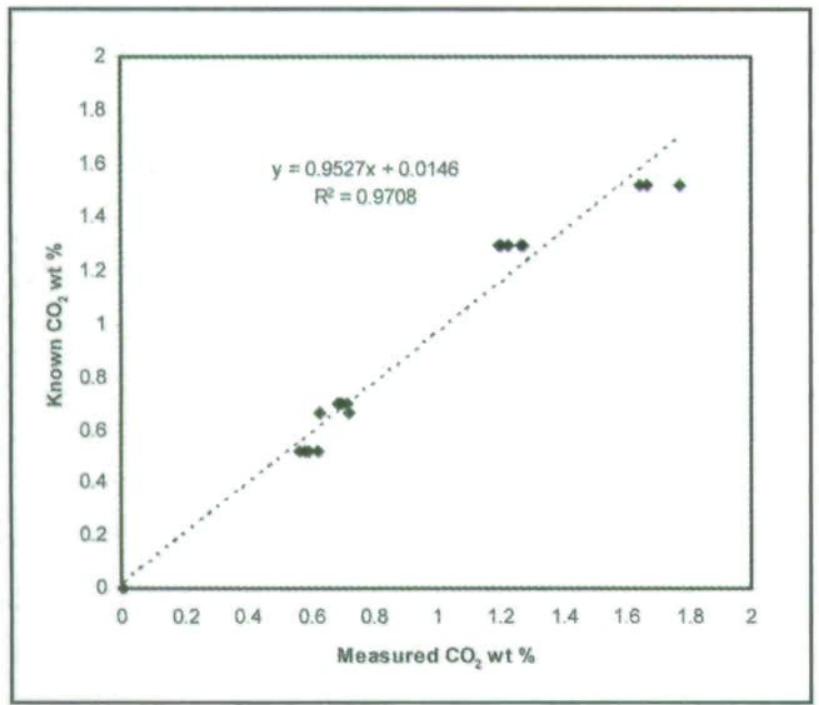

Figure 4. SIMS $\mathrm{CO}_{2}$ calibration curve. A plot of known cordierite $\mathrm{CO}_{2}$ content versus measured $\mathrm{CO}_{2}$
$=0.70+/-0.05 \mathrm{wt} \%$ ) was employed as the oxygen standard. The volatile contents of AMNH were determined independently by stepped-heating mass spectrometry (Harley pers.comm). The oxygen contents of thirty-two cordierites were determined using the method outlined above. Representative cordierite analyses and volatile oxygen contents from each sample are presented in Tables 1 to 3. The reported values are the mean of 15-30 individual analyses. Errors in the volatile oxygen content were calculated using standard error propagation techniques, incorporating the uncertainty in the analytical population and the calibration. The cations were assumed to be stoichiometric and therefore the error in the analytical population included the standard deviation of the measured oxygen content and the error associated with the analysis of each cation.

\section{Secondary-ion mass spectrometry (SIMS) of $\mathrm{H}_{2} \mathrm{O}$ and $\mathrm{CO}_{2}$ in cordierite}

Carrington and Harley (1996) developed and pioneered the use of SIMS for determining the volatile contents of cordierite. SIMS has a marked advantage over many forms of volatile analysis as it is able to obtain in situ $\mathrm{H}$ and $\mathrm{C}$ data simultaneously from a relatively small area (ca. $30 \mu \mathrm{m}$ in diameter). The $\mathrm{H}_{2} \mathrm{O}$ and $\mathrm{CO}_{2}$ content of cordierite was analysed in 24 samples from the Ballachulish thermal aureole, Scotland, using the CAMECA ims-4f ion-microprobe at the University of Edinburgh. ${ }^{12} \mathrm{C} /{ }^{28} \mathrm{Si}$ and ${ }^{1} \mathrm{H} /{ }^{28} \mathrm{Si}$ isotopic ratios were obtained using a $\mathrm{O}^{-}$primary-beam sourced from a duoplasmatron with an acceleration energy of $10 \mathrm{kV}$ and a beam current of $8 \mathrm{nA}$. The extraction energy was $4.5 \mathrm{kV}$ and the energy offset was $75 \mathrm{~V}$. Each analysis involved a 2 minute burn-in time followed by 25 cycles of $5 \mathrm{~s}$ counts for each isotope. Spot analyses produce pits in the sample measuring between $20-30 \mu \mathrm{m}$ in diameter and $3 \mu \mathrm{m}$ in depth. The mean of the last 10 cycles is taken as the final result, thereby avoiding surface contamination (Harley et al., 2002).

${ }^{12} \mathrm{C} /{ }^{28} \mathrm{Si}$ and ${ }^{1} \mathrm{H} /{ }^{28} \mathrm{Si}$ isotopic ratios were converted to wt $\% \mathrm{H}_{2} \mathrm{O}$ and $\mathrm{CO}_{2}$ using mineral standards of known composition. Standard 81/90 (supplied by V.Schenk and used by Moazzen et al., 2001 and Harley et al. 2002) has $\mathrm{XMg}=0.66 ; \mathrm{H}_{2} \mathrm{O}=0.80+/-0.06$ weight $\%$; and $\mathrm{CO}_{2}=$ $1.30+/-0.06$ weight $\%$. Several other cordierites of known composition including AMNH (previously described as an O standard) were analysed in order to further constrain the calibration curves (Harley and Hinton pers.comm). All SIMS cordierite standards were analysed independently via a combination of Stepped Heating Mass Spectrometry (SHMS), Karl-Fischer titration (KFT) and H-manometry (Harley personal communication). The standard deviation of the SIMS analytical population was combined with the uncertainty in the composition of the 'knowns' to derive calibration curves for $\mathrm{H}_{2} \mathrm{O}$ and $\mathrm{CO}_{2}$ with estimated uncertainties of $+/-0.094$ and 0.089 weight $\%$ respectively (Figures 3 and 4). Measured values of $\mathrm{H}_{2} \mathrm{O}$ and $\mathrm{CO}_{2}$ wt \% were 
Table 4: SIMS determined $\mathrm{H}_{2} \mathrm{O}, \mathrm{CO}_{2}$ and volatile oxygen contents for samples from the Ballachulish and Etive thermal aureoles. " indicates data from Moazzen et al. (2001).

\begin{tabular}{|c|c|c|c|c|c|c|c|c|}
\hline Sample & MRB2c & MRB4 & MRB5 & MRB7 & MRB 10 & MRB 12 & MRB 13 & MRB 14 \\
\hline $\mathrm{H}_{2} \mathrm{O}$ wt $\%$ & 0.97 & 1.04 & 0.94 & 1.05 & 1.59 & 1.07 & 1.52 & 1.18 \\
\hline Error +/ - & 0.14 & 0.11 & 0.1 & 0.14 & 0.15 & 0.13 & 0.15 & 0.12 \\
\hline $\mathrm{CO}_{2}$ wt $\%$ & 0.11 & 0.13 & 0.17 & 0.21 & 0.27 & 0.19 & 0.19 & 0.17 \\
\hline Error +/- & 0.09 & 0.09 & 0.09 & 0.1 & 0.09 & 0.09 & 0.09 & 0.09 \\
\hline $\mathrm{O}\left(\mathrm{H}_{2} \mathrm{O}\right)$ & 0.86 & 0.92 & 0.83 & 0.94 & 1.41 & 0.95 & 1.35 & 1.05 \\
\hline $\mathrm{O}\left(\mathrm{CO}_{2}\right)$ & 0.08 & 0.1 & 0.12 & 0.16 & 0.20 & 0.14 & 0.14 & 0.12 \\
\hline Volatile O wt \% & 0.94 & 1.02 & 0.96 & 1.09 & 1.61 & 1.09 & 1.49 & 1.17 \\
\hline Error $+1-$ & 0.16 & 0.15 & 0.14 & 0.17 & 0.18 & 0.16 & 0.17 & 0.15 \\
\hline Sample & MRB 15 & MRB16A & MRB 16D & MRB 16E & MRB 16F & MRB 16G & MRB19 & MRB21 \\
\hline $\mathrm{H}_{2} \mathrm{O}$ wt $\%$ & 1.13 & 1.15 & 1.16 & 1.16 & 1.20 & 1.50 & 1.61 & 1.62 \\
\hline Error +/- & 0.15 & 0.15 & 0.14 & 0.13 & 0.10 & 0.12 & 0.15 & 0.21 \\
\hline $\mathrm{CO}_{2}$ wt $\%$ & 0.20 & 0.20 & 0.20 & 0.16 & 0.22 & 0.14 & 0.24 & 0.19 \\
\hline Error +/- & 0.09 & 0.09 & 0.11 & 0.09 & 0.09 & 0.09 & 0.11 & 0.11 \\
\hline $\mathrm{O}\left(\mathrm{H}_{2} \mathrm{O}\right)$ & 1.01 & 1.02 & 1.03 & 1.03 & 1.07 & 1.33 & 1.43 & 1.44 \\
\hline $\mathrm{O}\left(\mathrm{CO}_{2}\right)$ & 0.14 & 0.14 & 0.15 & 0.12 & 0.16 & 0.10 & 0.18 & 0.14 \\
\hline Volatile O wt \% & 1.15 & 1.17 & 1.18 & 1.14 & 1.23 & 1.43 & 1.61 & 1.58 \\
\hline Error +/- & 0.17 & 0.17 & 0.18 & 0.16 & 0.14 & 0.15 & 0.18 & 0.24 \\
\hline Sample & MRB22 & MRB23 & MRB24 & MRB27 & M166a* & M166d* & M171* & $\mathrm{M187}^{*}$ \\
\hline $\mathrm{H}_{2} \mathrm{O}$ wt $\%$ & 1.24 & 1.18 & 1.12 & 1.18 & 0.88 & 0.9 & 1.49 & 1.44 \\
\hline Error +/- & 0.19 & 0.16 & 0.13 & 0.17 & 0.13 & 0.08 & 0.09 & 0.11 \\
\hline $\mathrm{CO}_{2}$ wt $\%$ & 0.47 & 0.44 & 0.45 & 0.27 & 0 & 0 & 0 & 0 \\
\hline Error +/- & 0.22 & 0.15 & 0.14 & 0.1 & 0 & 0 & 0 & 0 \\
\hline $\mathrm{O}\left(\mathrm{H}_{2} \mathrm{O}\right)$ & 1.1 & 1.05 & 1 & 1.05 & 0.78 & 0.8 & 1.32 & 1.28 \\
\hline $\mathrm{O}\left(\mathrm{CO}_{2}\right)$ & 0.34 & 0.32 & 0.33 & 0.19 & 0 & 0 & 0 & 0 \\
\hline Volatile O wt $\%$ & 1.44 & 1.37 & 1.32 & 1.24 & 0.78 & 0.8 & 1.32 & 1.28 \\
\hline Error $+/-$ & 0.29 & 0.22 & 0.19 & 0.2 & 0.13 & 0.08 & 0.09 & 0.11 \\
\hline
\end{tabular}

then converted to volatile oxygen contents wt \% (Table 4).

\section{Fourier-transform infra-red spectroscopy (FTIR) of $\mathrm{H}_{2} \mathrm{O}$ and $\mathrm{CO}_{2}$ in cordierite}

FTIR has been employed successfully as an analytical technique for determining the volatile contents of cordierite (e.g. Vry et al. 1990; Kalt, 2000, Rigby et al., 2008; Rigby and Droop, 2008). The water and $\mathrm{CO}_{2}$ content of all cordierite samples were determined by high-resolution Fourier-Transform Infrared Spectroscopy (FTIR), using the Bruker HS 102 machine at the Geoinstitute in Bayreuth. The HS 102 is set with an optical microscope, a GLOBAR mid-infrared source, a $\mathrm{He}-\mathrm{Ne}$ laser controlled movable mirror, a $\mathrm{KBr}-\mathrm{Ga}$ beam splitter, and a MCT detector (Kalt, 2000). The spectra were collected in situ from approximately $100 \mu \mathrm{m}$ thick, double polished thin-sections. 200 scans were run per analysis using a beam diameter of 15 to $20 \mu \mathrm{m}$. Blanks were run once per hour and backgrounds were uniformly subtracted as standard from all spectra. The IR working curve for $\mathrm{H}_{2} \mathrm{O}$ was calibrated using eight cordierites of known composition. The $\mathrm{CO}_{2}$ and $\mathrm{H}_{2} \mathrm{O}$ content of each standard for the calibration was determined independently via a combination of SHMS and SIMS. The $\mathrm{H}_{2} \mathrm{O}$ contents were also verified independently by KFT. Four of the standards were prepared as three separate single polished crystals, each of which had been cut parallel to one the crystallographic axes. The peak height absorbance for a single standard was calculated as the mean peak-height absorbance from the three crystallographic axes. Separate crystals were not available for the four remaining cordierite standards therefore the mean peak height absorbance was recorded from over 50 spot analyses from polished sections of each sample. The $\mathrm{H}_{2} \mathrm{O}$ working curve thus represents the mean peakheight absorbance (including the maximum and minimum absorbance obtained from different crystallographic orientations) versus independently determined $\mathrm{H}_{2} \mathrm{O}$ content. The $\mathrm{H}_{2} \mathrm{O}$ peak height absorbance was highly reproducible, yielding a calibration curve with an excellent fit (Figure 5). The working curve was used in all analyses of cordierite to convert peak height absorbance to weight $\% \mathrm{H}_{2} \mathrm{O}$.

The $\mathrm{CO}_{2}$ working curve of Vry et al. (1990) was used to calculate the weight $\% \mathrm{CO}_{2}$ from the measured peak height absorbance. Vry et al., (1990) measured absorbance from $280 \mu \mathrm{m}$ thick pellets that consisted of $1 / 34$ cordierite and $33 / 34 \mathrm{KBr}$, therefore absorbance was recalculated to $100 \%$ cordierite and $100 \mu \mathrm{m}$ thick sections. Kalt (2000) analysed three well-known $\mathrm{CO}_{2}$ 


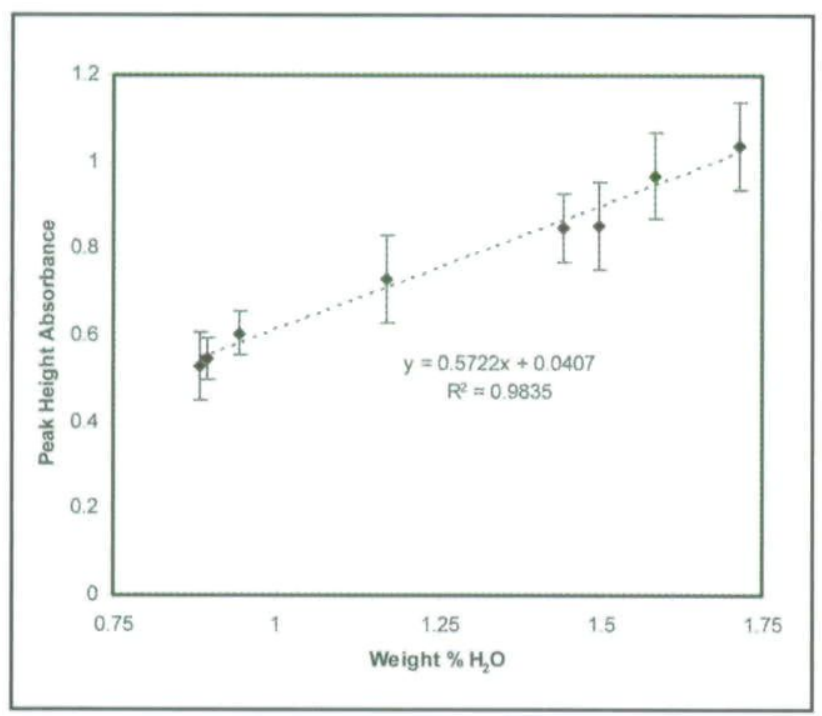

Figure 5. FTIR calibration curve for $\mathrm{H}_{2} \mathrm{O}$.

cordierite standards via FTIR in order to check the applicability of the Vry et al. (1990) calibration. These FTIR-determined results were in good agreement with independently determined $\mathrm{CO}_{2}$ concentrations thereby demonstrating that the Vry et al. (1990) calibration is valid and applicable.

FTIR analyses performed on single polished thin sections are sensitive to orientation. Maximum absorption occurs for both $\mathrm{H}_{2} \mathrm{O}$ and $\mathrm{CO}_{2}$ when their dipole moment is oriented parallel to the electrical field vector. All other orientations will give lower absorbance peaks. Kalt (2000) estimated the magnitude of this effect by repeating several spot measurements after rotating the sample on the microscope stage. The orientation effect was found to be at a minimum of $2 \%$ for $\mathrm{H}_{2} \mathrm{O}$ and $5 \%$ for $\mathrm{CO}_{2}$, and at maximum of $30 \%$ and $50 \%$ for $\mathrm{H}_{2} \mathrm{O}$ and $\mathrm{CO}_{2}$, respectively. In spite of this outcome Kalt (2000) elucidates that the measured peak height

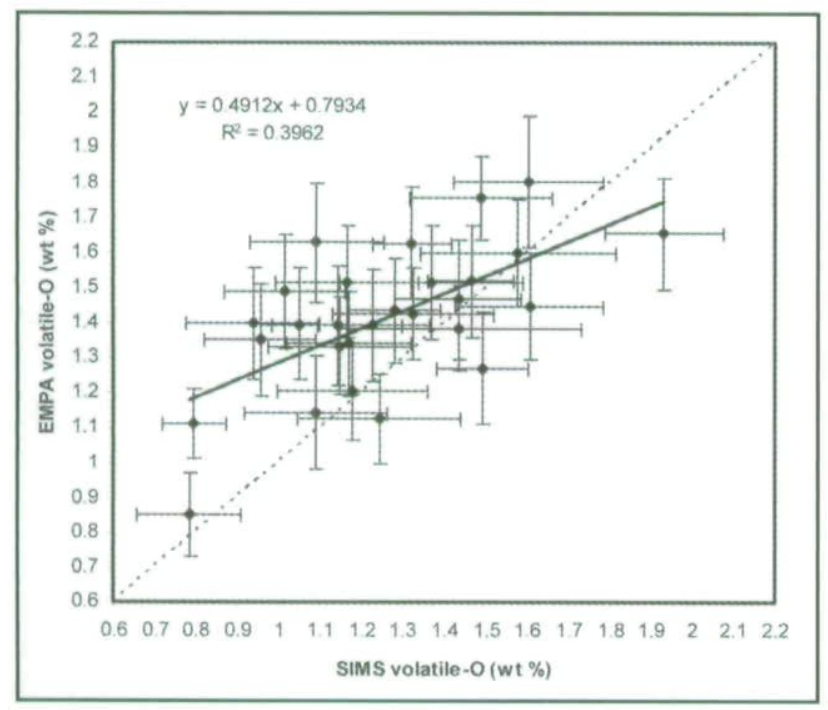

Figure 6. A comparison of LEEMPA determined volatile oxygen contents for various cordierite samples versus those determined by SIMS. absorbance obtained from independently analysed cordierite standards is directly related to the $\mathrm{H}_{2} \mathrm{O}$ and $\mathrm{CO}_{2}$ contents, because their concentration was determined by bulk-chemical methods that are insensitive to orientation (e.g. SHMS, and SIMS). The orientation effect only becomes important when comparing the $\mathrm{H}_{2} \mathrm{O}$ and $\mathrm{CO}_{2}$ contents of different grains within the same sample. In order to justifiably infer any variation between grains there must be a systematic difference greater than the potential error introduced by the orientation effect. Thus it is imperative with FTIR spectroscopy on polished thin-sections that the average $\mathrm{H}_{2} \mathrm{O}$ and $\mathrm{CO}_{2}$ contents are calculated from several grains in each sample. Moreover, repeated spot measurements should be taken after rotating the stage in order to determine the maximum absorption in the plane of the section.

Naturally occurring cordierite commonly forms either sector-twinned porphyroblasts or polycrystalline patches that show extensive sub-grain development. The orientation effect is thus reduced as a single analysis of one part of a grain often incorporates numerous crystallographic domains. All FTIR analyses were taken from cordierite domains that were inclusion-free and distant from cracks and alteration. $\mathrm{H}_{2} \mathrm{O}$ and $\mathrm{CO}_{2}$ contents have been calculated from several grains in each sample. Errors in weight $\% \mathrm{CO}_{2}$ and $\mathrm{H}_{2} \mathrm{O}$ were calculated using standard error propagation techniques, incorporating the uncertainty in the analytical population (which is introduced mainly by the orientation effect) and the calibration. Measured values of $\mathrm{H}_{2} \mathrm{O}$ and $\mathrm{CO}_{2}$ weight \% were then converted to volatile oxygen contents weight $\%$ (Tables 5-6).

\section{Results}

Figure 6 illustrates the measured volatile oxygen contents obtained via EPMA versus those determined by

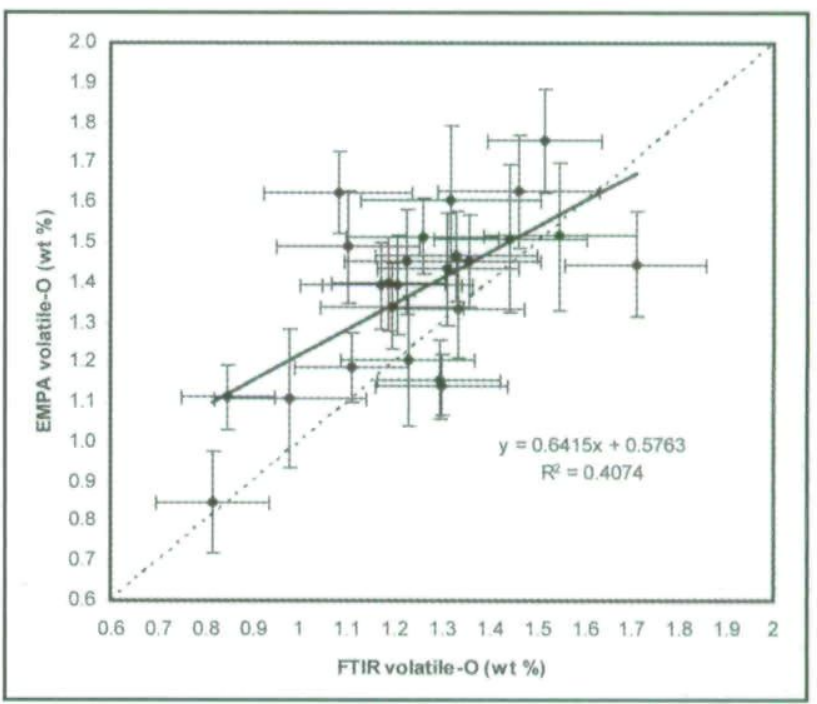

Figure 7. A comparison of LEEMPA determined volatile oxygen contents for various cordierite samples versus those determined by FTIR. 
Table 5: FTIR determined $\mathrm{H}_{2} \mathrm{O}, \mathrm{CO}_{2}$ and volatile oxygen contents for samples from the Ballachulish thermal aureole.

\begin{tabular}{|c|c|c|c|c|c|c|c|}
\hline \multirow[t]{2}{*}{ Sample } & MRB & MRB & MRB & MRB & MRB & MRB & MRB \\
\hline & $2 c$ & 4 & 5 & 7 & 10 & 12 & 13 \\
\hline $\mathrm{H}_{2} \mathrm{O}$ wt $\%$ & 1.26 & 1.18 & 1.39 & 1.38 & 1.76 & 1.58 & 1.61 \\
\hline Error $+/-$ & 0.11 & 0.14 & 0.09 & 0.06 & 0.12 & 0.14 & 0.12 \\
\hline $\mathrm{CO}_{2}$ wt $\%$ & 0.10 & 0.07 & 0.17 & 0.10 & 0.20 & 0.08 & 0.12 \\
\hline Error $+/-$ & 0.02 & 0.02 & 0.07 & 0.05 & 0.04 & 0.03 & 0.04 \\
\hline $\mathrm{O}\left(\mathrm{H}_{2} \mathrm{O}\right)$ & 1.12 & 1.05 & 1.24 & 1.22 & 1.56 & 1.40 & 1.43 \\
\hline $\mathrm{O}\left(\mathrm{CO}_{2}\right)$ & 0.07 & 0.05 & 0.12 & 0.08 & 0.15 & 0.06 & 0.09 \\
\hline Volatile O wt \% & 1.19 & 1.10 & 1.36 & 1.30 & 1.71 & 1.46 & 1.52 \\
\hline \multirow[t]{3}{*}{ Error +/- } & 0.12 & 0.14 & 0.11 & 0.08 & 0.13 & 0.14 & 0.13 \\
\hline & MRB & MRB & MRB & MRB & MRB & MRB & MRB \\
\hline & 14 & 15 & $16 A$ & $16 \mathrm{D}$ & $16 E$ & $16 F$ & $16 G$ \\
\hline $\mathrm{H}_{2} \mathrm{O}$ wt $\%$ & 1.27 & 1.38 & 1.30 & 1.26 & 1.23 & 1.26 & 1.38 \\
\hline Error $+/-$ & 0.10 & 0.11 & 0.08 & 0.14 & 0.10 & 0.11 & 0.09 \\
\hline $\mathrm{CO}_{2}$ wt $\%$ & 0.09 & 0.15 & 0.15 & 0.15 & 0.11 & 0.12 & 0.15 \\
\hline Error +1- & 0.04 & 0.05 & 0.06 & 0.08 & 0.04 & 0.05 & 0.07 \\
\hline $\mathrm{O}\left(\mathrm{H}_{2} \mathrm{O}\right)$ & 1.13 & 1.22 & 1.15 & 1.12 & 1.09 & 1.12 & 1.22 \\
\hline $\mathrm{O}\left(\mathrm{CO}_{2}\right)$ & 0.06 & 0.11 & 0.11 & 0.11 & 0.08 & 0.09 & 0.11 \\
\hline Volatile O wt \% & 1.20 & 1.33 & 1.26 & 1.23 & 1.17 & 1.21 & 1.33 \\
\hline Error+/- & 0.11 & 0.12 & 0.10 & 0.16 & 0.11 & 0.12 & 0.11 \\
\hline
\end{tabular}

Table 6. FTIR determined $\mathrm{H}_{2} \mathrm{O}, \mathrm{CO}_{2}$ and volatile oxygen contents for samples from the Etive thermal aureole and Madagascar

\begin{tabular}{|c|c|c|c|c|c|c|c|c|c|c|c|}
\hline & $\mathbf{M}$ & $\mathbf{M}$ & $\mathbf{M}$ & $\mathbf{M}$ & $\mathbf{M M}$ & $\mathbf{M}$ & $\mathbf{M M}$ & & BB & & \\
\hline Sample & $166 a$ & $166 d$ & 171 & 174 & $186 a$ & 187 & $193 Y$ & 305 & $14 b$ & 1016 & 799 \\
\hline $\mathrm{H}_{2} \mathrm{O}$ wt $\%$ & 0.84 & 0.87 & 1.16 & 1.15 & 1.37 & 1.38 & 1.19 & 1.63 & 1.74 & 1.49 & 1.10 \\
\hline Error $+/-$ & 0.13 & 0.08 & 0.09 & 0.08 & 0.09 & 0.11 & 0.12 & 0.18 & 0.18 & 0.18 & 0.17 \\
\hline $\mathrm{CO}_{2}$ wt $\%$ & 0.09 & 0.10 & 0.07 & 0.12 & 0.11 & 0.12 & 0.23 & 0.00 & 0.00 & 0.00 & 0.00 \\
\hline Error+/- & 0.03 & 0.03 & 0.04 & 0.04 & 0.05 & 0.08 & 0.06 & 0.04 & 0.04 & 0.04 & 0.04 \\
\hline $\mathrm{O}\left(\mathrm{H}_{2} \mathrm{O}\right)$ & 0.75 & 0.78 & 1.03 & 1.02 & 1.21 & 1.23 & 1.06 & 1.44 & 1.55 & 1.32 & 0.98 \\
\hline $\mathrm{O}\left(\mathrm{CO}_{2}\right)$ & 0.07 & 0.07 & 0.05 & 0.09 & 0.08 & 0.09 & 0.17 & 0.00 & 0.00 & 0.00 & 0.00 \\
\hline Volatile O wt $\%$ & 0.82 & 0.85 & 1.08 & 1.11 & 1.29 & 1.31 & 1.23 & 1.44 & 1.55 & 1.32 & 0.98 \\
\hline Error $+/-$ & 0.13 & 0.08 & 0.10 & 0.09 & 0.10 & 0.14 & 0.13 & 0.18 & 0.18 & 0.18 & 0.17 \\
\hline
\end{tabular}

SIMS. A linear regression through the data yields an $\mathrm{R}^{2}$ value of 0.3962 , which indicates there is a positive correlation between the two data sets. Figure 7 illustrates the measured volatile oxygen contents obtained via EPMA versus those determined by FTIR. The statistical analysis reveals results that are similar to those obtained for the SIMS data. A linear regression yields an $R^{2}$ value of 0.4074 , which also indicates there is also positive correlation. The similarity in the correlation coefficients for the SIMS versus EPMA and the FTIR versus EPMA data suggests that there are only minor differences between the two independent methods. However, taking into account the maximum error on each data point then 8 out 28 samples fail to fall on the ideal 1:1 correlation curve (dotted line on Figure 6) for the SIMS data. Conversely, for FTIR only 3 out 25 data points fail to plot on the ideal regression line, which indicates that the FTIR data, within error, yields a closer fit to the EPMA data than the SIMS. Figure 8 illustrates a comparison of the volatile oxygen contents obtained from FTIR versus those determined from SIMS. A linear regression through the data yields an $\mathrm{R}^{2}$ value of 0.5585 , indicating there is a correlation between the two datasets. More importantly, whilst the data obtained from EPMA versus SIMS/FTIR does show significant scatter, the correlation is comparable to that obtained from the well-established methods i.e. FTIR versus SIMS data shows a similar scatter to that obtained by EPMA.

\section{Discussion}

Despite scatter in the data there is generally a correlation between the volatile-O contents of cordierite determined by EPMA and those determined by SIMS or FTIR. The correlation between the SIMS/FTIR and EPMA data is similar to the correlation obtained from a comparison of the SIMS versus FTIR data (Figure 8). Any discrepancies between data from SIMS and LEEPMA maybe attributed to the fact that the former will also detect $\mathrm{C}$ and $\mathrm{H}$ in any methane present. However, as this should yield volatile-O contents that are greater than those determined by EPMA, which is not what is observed, and therefore is unlikely to be an important factor.

SIMS and FTIR are traditional and well-established techniques and the fact that the EPMA data yields comparable results to both these techniques is 


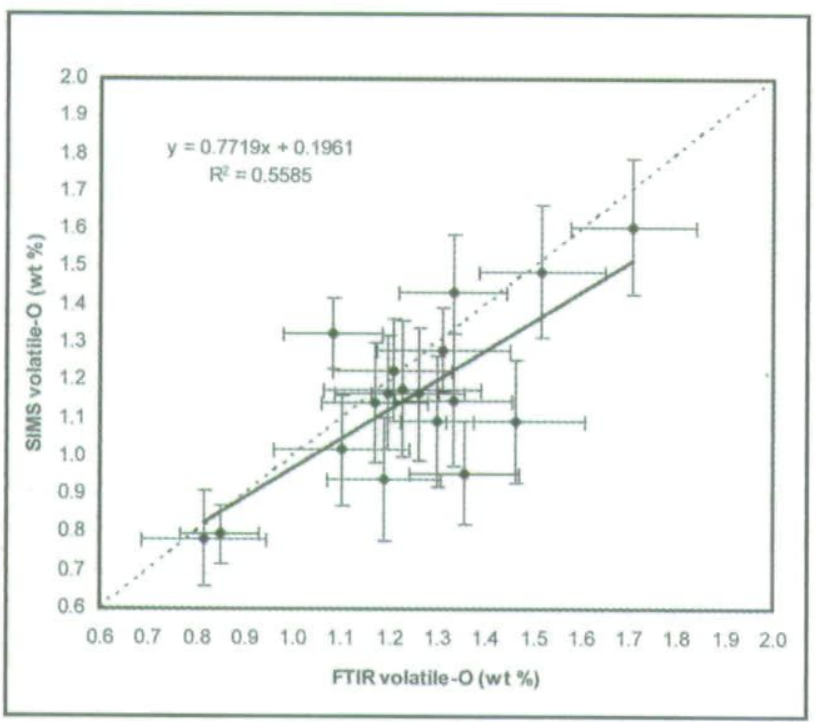

Figure 8. A comparison of volatile oxygen contents for various cordierite samples determined by SIMS and FTIR.

encouraging. Furthermore, the margins of error for volatile oxygen contents obtained by EMPA ( 9 to $14 \%$ relative) are comparable and, in some instances, better than those determined by SIMS ( 7 to $20 \%$ relative) and FTIR (6 to $18 \%$ relative). However, regardless of which independent technique was employed, EPMA-O contents do generally tend to produce higher results. This may occur for a number of possible reasons:

\section{Spectral phenomena.}

Bulk chemical differences between the unknowns and standards are known to cause spurious effects upon the O peak shape and peak position. Even though cordierite standards were employed to analyze unknown cordierites it is not known whether slight compositional variations between different cordierite standards would induce differences in the $\mathrm{O}$ spectra that may explain why the EPMA and independent volatile-O contents do not agree more closely. In order to rule out this possibility WDS spectral scans of $\mathrm{O}$ were obtained from several cordierites of known composition. Figure 9 demonstrates that that there is no noticeable difference in either the shape or position of the O peak.

\section{Un-analysed cations and $\mathrm{Fe}^{3+}$}

At present the EMPA-determined volatile-O contents are calculated by difference assuming stoichiometry in the measured cations. Only the major-element cations $\mathrm{Fe}$, $\mathrm{Mn}, \mathrm{Mg}, \mathrm{Al}, \mathrm{Si}, \mathrm{Na}, \mathrm{K}$ were analyzed. It is possible that trace amounts of minor elements such $\mathrm{Be}, \mathrm{Li}, \mathrm{Ba}$ and $\mathrm{Ca}$ are also present within cordierite and contribute to the total $\mathrm{O}$ budget. The presence of any un-analyzed cations would lead to an apparent increase in the volatile-O content. However, for most cordierite samples the analytical totals argue against any significant input from un-analyzed cations. Taking into account the presence of 0.1 to 0.2 weight $\% \mathrm{C}$ (determined from FTIR or SIMS analyses) most analytical totals fall between 99.5 to $100.5 \%$, which attests to the high quality of the analyses and the lack of significant $\mathrm{O}$ input from un-analyzed

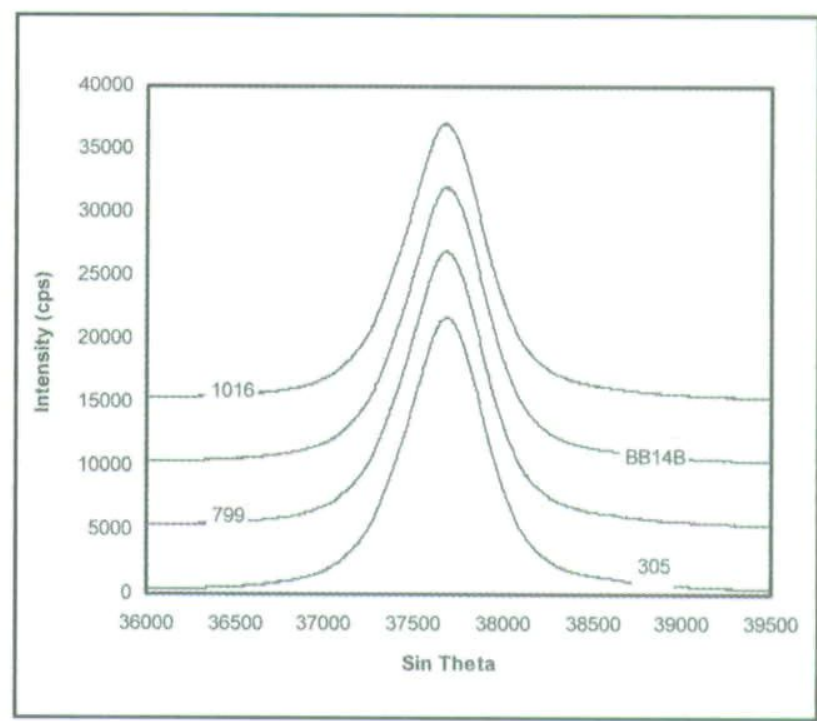

Figure 9. A comparison of the $\mathrm{O}$ peaks obtained from different cordierites of known composition. There is no discernible difference in either the shape or peak position of these cordierites O spectra.

cations. If analytical totals are low by $>0.5$ weight $\%$ then the potential contribution from un-analyzed elements must be evaluated. McGuire et al., (1992) warned that the analysis of Fe-bearing minerals may result in the calculation of imprecise $\mathrm{O}$ contents if the Fe valence state is unaccounted for. Hitherto it has not been possible to determine the $\mathrm{Fe}^{3+} \Sigma \mathrm{Fe}$ ratio in Fe-bearing minerals via EPMA. If $\mathrm{Fe}$ is present in appreciable amounts the $\mathrm{Fe}^{3+}$ content can be estimated from EPMA results using the stoichiometric criteria of Droop (1987) or determined precisely using Mössbauer spectroscopy. For present purposes, however, this is inconsequential as the amount of $\mathrm{Fe}^{3+}$ in cordierite rarely exceeds 0.004 cations pfu (Geiger et al., 2000).

\section{Mineral-surface $O$ or background $O$}

In view of the high surface-sensitivity of EPMA (Bastin and Heijligers, 1991), WDS spectral scans of O were obtained from $\mathrm{Co}$ in order to ascertain the potential interference from mineral-surface or background $\mathrm{O}$. The Co sample was thoroughly cleaned and polished immediately prior to analysis in order to remove any potential oxidised coat. The surface or background $\mathrm{O}$ content of Co was determined during two separate analytical sessions in order assess the reproducibility. At $10 \mathrm{kV}$ and $40 \mathrm{nA}$ the two spectra collected from two different areas on the same specimen during different analytical sessions yield essentially identical results $\sim 300$ counts per second (Figure 10). At the same analytical conditions cordierite AMNH yields $\sim 22000$ O counts per second. If a comparable amount of surface or background $\mathrm{O}$ was present during the quantitative analysis of cordierite then this would cause an enhancement of the $\mathrm{O}$ peak count rate by around $1.3 \%$ and would adequately explain the over-estimation of EPMA-determined volatile-O contents. At present it is not known whether the $\mathrm{O}$ peak detected on Co was 


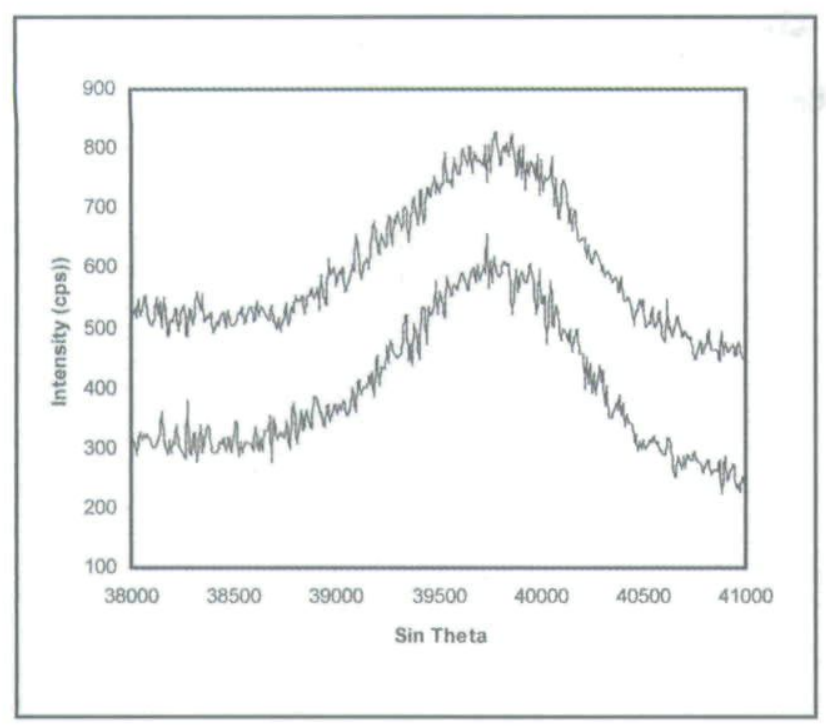

Figure 10. O peaks detected on freshly polished Co. Spectra collected at $10 \mathrm{kV}$ and $40 \mathrm{nA}$

inherent to that sample or whether similar $O$ peaks will be detected on all other non-O bearing elements/compounds. In order to rectify this potential problem, background levels of oxygen must be ascertained prior to quantitative analysis. The analysis of non-oxygen bearing compounds during the same analytical session would provide a means for establishing background levels.

\section{Oxygen input from the air jet}

As discussed previously, in order to minimize the potential build-up of contaminants on the sample an oxygen air-jet was employed during all quantitative analyses of oxygen. At first this may appear counterintuitive, as one is analyzing for oxygen and the extra oxygen added from the air jet may contribute to the total oxygen budget. In order to test this hypothesis, oxygen spectra were collected from a fresh sample of LiF using the air jet and without it. LiF was chosen as it is a non-oxygen bearing compound and therefore the analysis will detect background oxygen levels only, which are more likely to show a rapid increase if the air jet does contribute to the total oxygen budget. Figure 11 demonstrates that there is no discernible contribution to the oxygen count rate by employing the air jet.

\section{Spatial resolution and within-sample beterogeneities}

Figures 6 and 7 illustrate that the EPMA-determined volatile-O content of some samples deviate significantly from those obtained by independent methods. The largest deviations may, in part, be explained by differences between the independent methods. For example, FTIR results generally agree more closely with EPMA results than SIMS. In spite of this, the samples showing the largest deviations are all known to contain moderately variable $\mathrm{H}_{2} \mathrm{O}$ and/or $\mathrm{CO}_{2}$ contents (as determined by SIMS and/or FTIR). In these samples that are known to be heterogeneous even smaller scale

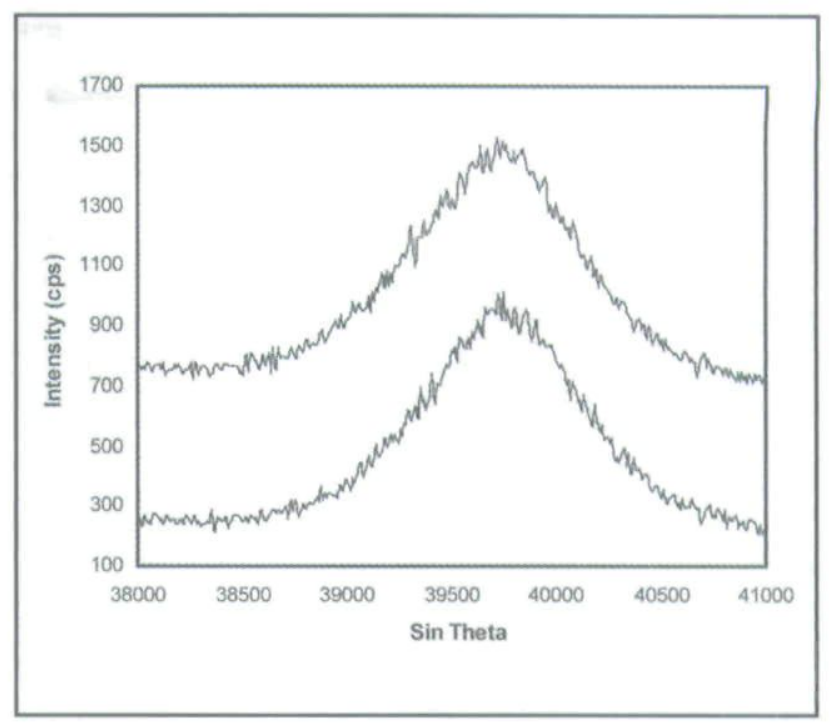

Figure 11. Oxygen spectra from collected LiF at $10 \mathrm{kV}$ and $40 \mathrm{nA}$. One spectra was collected whilst employing the air jet and the other was collected without the air jet. There is no discernible difference between the two oxygen spectra.

variations might be 'ironed-out' over the $20-30 \mu \mathrm{m}$ spatial resolution obtained by FTIR or SIMS. The increased spatial resolution of EPMA enables small scale $(\sim 2 \mu \mathrm{m})$ heterogeneities to be determined which, in turn, may reflect why the EPMA results for heterogeneous samples deviate even more from those obtained by independent methods. For example, EPMA-determined zoning profiles from a single grain within sample MRB 14 reveal substantial variations in the total-volatile $\mathrm{O}$ content over distances as small as $5 \mu \mathrm{m}$ (Figure 12).

\section{Non-stoichiometry}

The main downfall inherent in the EPMA method is centred on the assumption that a mineral will have a stoichiometric O content. McGuire et al. (1992) highlighted the potential danger in this assumption. If in some instances non-stoichiometry does apply then the method for calculating either the volatile-O content in cordierite or the $\mathrm{H}_{2} \mathrm{O}$ content in other minerals is rendered inadequate.

\section{Conclusions}

EPMA of oxygen in cordierite yields data that is comparable to that obtained from independent, wellestablished analytical techniques. The encouraging results and margins of error suggest that oxygen can be routinely analyzed with the degree of accuracy obtained for other elements and further research on this matter should be conducted. EPMA of oxygen, in addition to the cations, can provide a method for determining the volatile oxygen content of cordierite or potentially the $\mathrm{OH}$ content of amphiboles and micas. The assumption inherent in this approach is that the cations and oxygen are present in stoichiometric proportions. If minerals are non-stochiometric the volatile oxygen or $\mathrm{OH}$ contents obtained by this method will be erroneous. EPMA of oxygen in non-volatile-bearing minerals would provide 


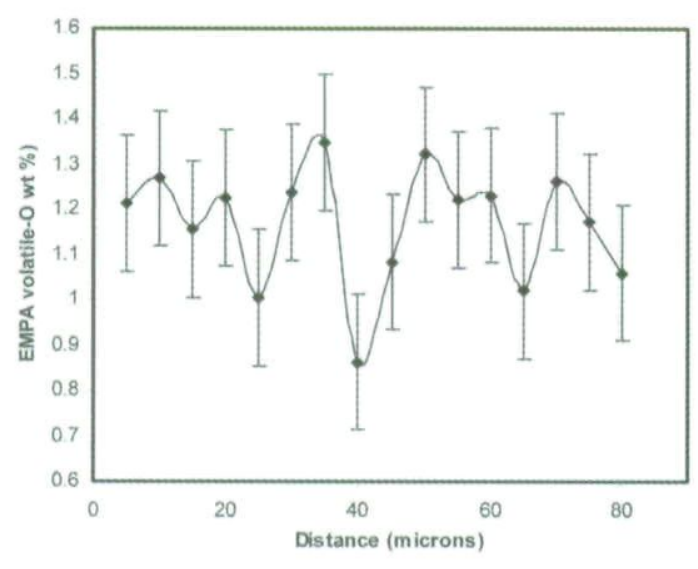

Figure 12. A LEEPMA-determined volatile-O zoning profile across a sub-grain free cordierite domain from sample MRB 14. Note the expanded $y$-axis.

a check on stoichiometry. However, the main down-fall inherent to this approach would be the presence of $\mathrm{Fe}^{3+}$. Even minor amounts of $\mathrm{Fe}^{3+}$ would raise the total oxygen budget leading to volatile oxygen or $\mathrm{H}_{2} \mathrm{O} / \mathrm{OH}$ contents that are over-estimated. If a mineral is both $\mathrm{Fe}^{3+}$ bearing and non-stoichiometric the oxygen from the analysis could not be attributed to either feature with any degree of certainty.

\section{Acknowledgements}

This paper was derived, in part, from the Ph.D. thesis of Martin J Rigby at the University of Manchester. The work was supported by a NERC research studentship (NER/S/A/2001/06308), which is gratefully acknowledged. NERC are also thanked for an ion probe grant (IMP231/0504) that enabled SIMS analysis to be conducted at the University of Edinburgh. Richard Hinton and John Craven are thanked for their assistance with the SIMS analysis. FTIR analysis was supported by the Marie Curie research training programme at the Bayrerische Geoinstitut. Bo Johanson and anonymous referee are thanked for their encouraging and critical reviews respectively. A. Bumby and J. Barton are thanked for the editorial handling.

\section{References}

Armstrong, J.T. (1988), Microbeam analysis - 1988, 469-476.

Armstrong, J.T. (1993). Microbeam analysis 2, 25-26

Bastin, G.F., and Heijligers, H.J.M. (1986). Quantitative electron probe microanalysis of ultra light elements. Journal of Microscopy and Spectroscopy, 11, 215-228.

Bastin, G.F., and Heijligers, H.J.M. (1990). Quantitative electron probe microanalysis of ultra light elements (B-O). Scanning, 12, 225-236.

Bastin, G.F., and Heijligers, H.J.M. (1991). Quantitative electron probe microanalysis of ultra light elements (B-O) In: K.F.J. Heinrich and D.E. Newbury (Editors). Electron Probe Quantitation, Plenum Press, New York, United States of America, 145pp.

Bastin, G.F., and Heijligers, H.J.M. (2000). Quantitative electron probe microanalysis of boron. Journal of Solid State Chemistry, 154, 177-187.
Carrington, D.P. and Harley, S.L. (1996). Cordierite as a monitor of fluid and melt water contents in the lower crust: An experimental calibration. Geology, 24, 647-650.

Droop, G. T. R. (1987). A general equation for estimating $\mathrm{Fe}^{3 *}$ concentrations in ferromagnesian silicates and oxides using stoichiometric criteria. Mineralogical Magazine, 51, 431-437

Droop, G. T. R. (1989). Reaction history of garnet-sapphirine granulites and conditions of Archaean high-pressure granulite-facies metamorphism in the Central Limpopo Mobile Belt, Zimbabwe. Journal of Metamorphic Geology, 7, 383-403.

Droop, G.T.R. and Moazzen, M. (2007). Contact metamorphism and partial melting of Dalradian pelites and semipelites in the southern sector of the Etive aureole. Scottish Journal of Geology, 43, 1-25.

Fischer, D.W. (1965). Effect of chemical combination on the X-ray emission spectra of oxygen and fluorine. Journal of Chemical Pbysics, 42, 3814

Geiger, C.A., Rager, H. and Czank, M. (2000). Cordierite III: the site occupation and concentration of $\mathrm{Fe}^{3+}$. Contributions to Mineralogy and Petrology, 140, 344-352.

Goldstein, J.I., Newbury, D.E., Echlin, P., Joy, D.C., Fiori, C.E. and Lifshin, E. (1992). Scanning Electron Microscopy and X-ray microanalysis. Plenum Press, New York, United States of America, 8i0pp.

Harley, S., Thompson, P., Henson, B.J., and Buick, I.S. (2002). Cordierite as a sensor of fluid conditions in high-grade metamorphism and crustal anatexis. Journal of Metamorphic Geology, 20, 71-86.

Harris, N. (1981). The application of spinel-bearing metapelites to P/T determinations: an example from South India. Contributions to Mineralogy and Petrology, 76, 229-233.

Kalt, A. (2000). Cordierite channel volatiles as evidence for dehydration melting: an example from high-temperature metapelites of the Bayerische Wald (Variscan belt, Germany). European Journal of Mineralogy. 12, $987-998$.

McGee, J.J., and Anovitz, L.M. (1996). EPMA of geologic materials from B to F. Revieus in Mineralogy, 33, 771-788.

McGuire, A.V., Francis, C.A., and Dyar, M.D. (1992). Mineral standards for EPMA of oxygen. American Mineralogist, 77, 1087-1091.

Moazzen, M., Droop, G.T.R. and Harte, B. (2001). Abrupt transition in $\mathrm{H}_{2} \mathrm{O}$ activity in the melt-present zone of a thermal aureole: Evidence from $\mathrm{H}_{2} \mathrm{O}$ contents of cordierites. Geology, 29, 311-314.

Nash, W.P., (1992), Analysis of oxygen with the electron microprobe: applications to hydrated glass and minerals. American Mineralogist, 77, 453-457.

Pattison, D.R.M. (1989). P-T conditions and the influence of graphite on pelitic phase relations in the Ballachulish aureole, Scotland. Journal of Petrology, 30, 1219-1244.

Pouchou, J.L. and Pichoir, F. (1991). Quantitative analysis of homogeneous or stratified microvolumes applying the model "PAP". In: K.F.J. Heinrich and D.E. Newburg (Editors), Electron Probe Quantitation, Plenum Press, New York, United States of America, 412pp.

Raudsepp, M. (1995). Recent advances in the electron-probe micro-analysis of minerals for the light elements. The Canadian Mineralogist, 33, 203-218. Reed, S.J.B. (1993). Electron Microprobe Analysis (2nd Edition) Cambridge University Press, Cambridge, United Kingdom, 260pp.

Reed, S.J.B. (1995). Electron Microprobe Analysis. In: J.P. Potts, F.W. Bowles, S.J.B. Reed, and R. Cave (Editors), Microprobe techniques in the Earth sciences. Chapman and Hall, London, United Kingdom, 419pp.

Reed, S.J.B and Buckley, A. (1998). Computer simulation applied to WD analysis. Microscopy and Microanalysis 4 (Supplement 2), 236-237.

Rigby, M.J., Droop, G.T.R. and Bromiley, G. (2008).Variations in fluid activity across the Etive thermal aureole, Scotland: evidence from cordierite volatile contents. Journal of Metamorphic Geology, 26, 331-346.

Rigby, M.J., and Droop, G.T.R. (2008). The cordierite fluid monitor: case studies for and against its potential application. European Journal of Mineralogy. DOI: 10.1127/0935-1221/2008/0020-1867.

Vry, J.K., Brown, P.E. and Valley, J.W., 1990. Cordierite volatile content and the role of $\mathrm{CO}_{2}$ in high-grade metamorphism. American Mineralogist, 75. 71-88.

Editorial handling: A Bumby 
Copyright of South African Journal of Geology is the property of Geological Society of South Africa and its content may not be copied or emailed to multiple sites or posted to a listserv without the copyright holder's express written permission. However, users may print, download, or email articles for individual use. 